\title{
General practitioners' opinions of health services available to their patients
}

\author{
Nicholas R Hicks, Ian A Baker
}

\begin{abstract}
Objectives-To establish a means for general practitioners to express their views about health services available to their patients, to identify services that general practitioners perceive as most in need of improvement, and to establish good working relations between the health authority's purchasing team and local general practitioners.

Design-Postal questionnaire survey of general practitioners.

Setting-Bristol and Weston health district.

Subjects-226 general practitioners, of whom 171 replied.

Main outcome measures-Scores of quality and quantity of hospital and community services, frequency that services were identified as priorities for improvement, and the nature of written comments received about services.

Results-There was considerable agreement among respondents about which services were adequate and which were inadequate. Most services were perceived as at least adequate in both quality and quantity, but seven services were perceived by more than $60 \%(102)$ of doctors as inadequate or worse in quantity and eight by $10 \%(17)$ of doctors as poor in quality. Orthopaedics, ophthalmology, care of elderly people, and physiotherapy were the services doctors most wanted improved.

Conclusions-A postal questionnaire is an acceptable and accurate method of obtaining general practitioners' views about services available to their patients. General practitioners' priorities differ from those obtained from hospital medical advisory mechanisms.
\end{abstract}

\section{Introduction}

Under the internal market, which began on 1 April, district health authorities must purchase health care for geographically defined populations in pursuit of "better health and value for money in health outcome terms." To make the best use of their resources purchasing authorities must form a population view of health care requirements, determine the effectiveness of current services, and identify priorities for change. Because the interests of providers cannot be assumed to correspond with those of the population new routes for obtaining advice are needed that are independent of the providers.

General practitioners are an important source of advice. They are independent of providers and act as agents of the public in obtaining secondary care. They have registered with them almost the whole of a district's resident population, and have direct contact with people with a wide range of health care needs. They are also able to see at first hand the effect of the provision (or lack of provision) of health care on patients and their families. Despite the importance of general practitioners' opinions little attention has been given to how general practitioners can contribute their views about health services to district health authorities.

We conducted a study to establish a means for all

\section{Scales for rating hospital and community services}

$\begin{array}{ll}\text { Quantity } & \text { Quality } \\ 1 \text { Over provided } & 1 \text { Excellent } \\ 2 \text { Ample } & 2 \text { Good } \\ 3 \text { Adequate } & 3 \text { Adequate } \\ 4 \text { Inadequate } & 4 \text { Poor } \\ 5 \text { Grossly inadequate } & 5 \text { Very poor } \\ 6 \text { Insufficient experience of service to be able to offer } \\ \text { an opinion }\end{array}$

general practitioners to express their views about health services available to their patients; to identify those services that general practitioners perceived as most in need of improvement, and to establish good working relations between the purchasing team of the health authority and local general practitioners.

\section{Methods}

A postal questionnaire for distribution to general practitioners was developed with advice from representatives from the district's general practice advisory committees. The questionnaire asked general practitioners to rate the quality and quantity of 24 hospital and 28 community services on a five point scale (box). They were asked to consider quantity of care as how much care is available, how accessible it is, and how long it takes to receive it and quality of care as how good care is once it is received. They were also asked to identify five hospital and five community services that they most wanted to see improved and to rank them in order of priority. The questionnaire included space for additional comments about each service and about services in general. It was piloted on 20 general practitioners in a neighbouring health district and minor amendments were made as a result.

All general practitioners whose main practice base was in Bristol and Weston health district were identified by the Avon Family Practitioner Committee. Each general practitioner was sent the questionnaire, a personally addressed covering letter, and a reply paid envelope. A reminder and a second copy of the questionnaire were sent to doctors who did not respond within three weeks.

The data were coded and entered into an IBM AT microcomputer. A $10 \%$ sample of the questionnaires was recoded to assess the frequency of coding errors, and a $10 \%$ sample of coded questionnaires was reentered to check for data entry errors. No coding or data entry errors were detected. Data were analysed with the software packages SPSS-PC ${ }^{2}$ and Lotus 1,2, 3 (release $2 \cdot 2$ ).

Scores, priorities, and comments were analysed separately. The number of respondents giving a particular score for each service was determined. Comments were counted and classified as either favourable or unfavourable, and the number of times a particular service was allocated to a particular priority was noted. The association between perceptions of
Correspondence to: $\mathrm{Dr}$ Hicks.

BM7 1991:302:991-3 
quality and quantity was explored by least squares linear regression.

Responses to the three different sections of the questionnaire were compared with each other to assess the internal validity of the study. The external validity of the survey was assessed by presenting the results to general practitioners in a series of 10 seminars held in health centres across the district and asking whether the aggregated results accurately reflected their opinions.

\section{Results}

We received 171 completed questionnaires from 226 general practitioners practising in Bristol and Weston health district.

\section{QUALITY AND QUANTITY SCORES}

The quality and quantity of most services were scored by most general practitioners as adequate or better. Seven of 52 services, however, were described by more than $102(60 \%)$ doctors as inadequate or grossly inadequate in quantity (table I) and eight were described by more than $17(10 \%)$ doctors as poor or very poor in quality (table II). Perceptions of the quantity of services available were generally less favourable than the perceptions of quality of service. Forty services were described by more than 34 (20\%) doctors as inadequate or grossly inadequate in quantity. By contrast, only one service was described by more than 34 doctors as poor or very poor in quality (table III).

TABLE I-Services perceived by more than 60\% (102) of general practitioners as inadequate or grossly inadequate in quantity

\begin{tabular}{lc}
\hline & $\begin{array}{c}\text { No of general practitioners } \\
(\mathbf{n}=171)\end{array}$ \\
\hline Hospital services: & \\
Orthopaedics & 162 \\
Ophthalmology & 146 \\
Neurology & 138 \\
Rheumatology & 129 \\
Community services: & 147 \\
Physiotherapy & 110 \\
Chiropody & 110 \\
Health visiting for elderly people & \\
\hline
\end{tabular}

TABLE II-Services perceived by more than $10 \%$ (17) of general practitioners to be of poor or very poor quality

\begin{tabular}{lc}
\hline & $\begin{array}{c}\text { No of general practitioners } \\
(\mathrm{n}=171)\end{array}$ \\
\hline Hospital services: & \\
Orthopaedics & 23 \\
Hospital care for elderly, mentally & 23 \\
$\quad$ infirm people & \\
Community services: & 42 \\
$\quad$ Health visiting for elderly people & 33 \\
$\quad$ Community care for elderly mentally & 29 \\
infirm people & 24 \\
Community care for elderly people & 24 \\
Respite care for elderly mentally & infirm people \\
Community psychiatric care & 23 \\
Alcohol and drug services & \\
\hline
\end{tabular}

TABLE III - Number of services considered inadequate by general practitioners

\begin{tabular}{lccc}
\hline $\begin{array}{l}\text { No of general practitioners } \\
\text { responding }(\mathrm{n}=171)\end{array}$ & $\begin{array}{c}\text { No of hospital services } \\
(\mathrm{n}=24)\end{array}$ & $\begin{array}{c}\text { No of community services } \\
(\mathrm{n}=28)\end{array}$ & $\begin{array}{c}\text { Total } \\
(\mathbf{n}=52)\end{array}$ \\
\hline $\begin{array}{l}\text { Quantity inadequate or grossly inadequate: } \\
0-34\end{array}$ & 9 & 3 & 12 \\
-68 & 7 & 10 & 17 \\
-103 & 4 & 12 & 16 \\
-137 & 1 & 2 & 3 \\
-171 & 3 & 1 & 4 \\
Quality poor or very poor: & 17 & 12 & 29 \\
$0-9$ & 5 & 10 & 15 \\
-17 & 2 & 3 & 5 \\
-26 & & 2 & 2 \\
-34 & & 1 & 1 \\
$>34$ & & & \\
\hline
\end{tabular}

The hospital and community services that received fewest complaints about quantity were child health clinics (nine), paediatric surgery (10), and oncology (10). The services that received fewest complaints about quality were dermatology, paediatric surgery, and infectious diseases (all none) and district nursing and community midwifery (two).

The relation between quality and quantity was explored by creating scattergrams mapping the percentage of respondents that perceived the quality of a service to be poor or very poor against the percentage of respondents that perceived the quantity of that same service to be inadequate or grossly inadequate. Perceptions of quality and quantity were more closely associated for hospital than for community services. The correlation coefficient ( $r$ ) between perceptions of quality and quantity was 0.77 for hospital services and $0 \cdot 41$ for community services.

\section{COMMENTS}

Services that were perceived as less than adequate in quantity or quality, or both, generally attracted more comments than those that were perceived as adequate. For instance, chest medicine, rated by 148 doctors as adequate or better in quantity and by 162 as adequate or better in quality, attracted only two comments, both of which were favourable. By contrast, ophthalmology, rated by 146 doctors as inadequate or worse in quantity and by 17 as poor or worse in quality, attracted 43 comments all of which were unfavourable.

Only six services received unfavourable comments from more than 20 doctors: ophthalmology (43), orthopaedics (33), neurology (24), general surgery (24), physiotherapy (21), and community psychiatric care $(21)$. Ten or more favourable comments were received for district nursing (13), hospice care (10), and open access radiology (10). Analysis of doctors' comments identified a wide variety of issues that caused frustration or difficulty. The most often mentioned concerns were the low standards of communication between hospital and general practitioner and the waiting times of patients.

\section{PRIORITIES}

Considerable agreement was found among respondents about the services that they considered priorities for improvement (table IV), with more than half of respondents identifying orthopaedics as the hospital service they most wanted to see improved. Among community services physiotherapy and care of elderly people were doctors' high priorities for improvement.

The responses to the three sections of the questionnaire were consistent with each other. For example, orthopaedics and ophthalmology not only received worse scores than other hospital services but received more adverse comments than any other service. They were also the two services that general practitioners most wanted to see improved.

Over half the general practitioners working in the district attended one of the seminars at which the survey's results were presented. At each seminar general practitioners confirmed that their views were accurately represented by the results of the survey. In addition, many general practitioners warmly welcomed the health authority seeking general practitioners' opinions about services.

\section{Discussion}

Health authorities can obtain general practitioners' views about services available to their patients and identify general practitioners' priorities for service improvements with a postal questionnaire. The response rate obtained in our survey $(76 \%)$, comparable with those in other postal surveys of general prac- 
TABLE IV - Hospital services that general practitioners most want to see improved

No of doctors:

First priority Second priority First to fifth priority

Orthopaedics

Ophthalmology

Care of elderly, mentally infirm people

Care of elderly people

Urology

Rheumatology

General surgery

Psychiatry

Neurology

Gynaecology
31

142

23

8

7
6
4

4

3
2

2

9
5
1
15
8
5
15
4

43
38
29
57
33
28
55
23 titioners ${ }^{45}$ suggests that the method is practicable and acceptable to general practitioners.

There was a remarkable consistency of opinion among general practitioners; $95 \%$ identified the quantity of orthopaedics as either inadequate or grossly inadequate and more than half identified this specialty as their top priority for improvement. There was also consistency of opinion about the services that general practitioners perceived as well provided. This suggests that it is possible to obtain a corporate view of general practitioners' opinions. General practitioners' views may not be as disparate as many believe.

There was a strong association between general practitioners' perceptions of quality and quantity of care, particularly for the hospital services $(r=0 \cdot 77)$. The correlation was lower for community services, perhaps because general practitioners feel better able to judge the different components of community care than those of hospital care. These results support the views of the Royal College of General Practitioners, Maxwell, ${ }^{7}$ and others that the quantity of or access to a service is an important component of quality.

Just as general practitioners are not well placed to judge the technical quality of hospital services, so hospital staff are not well placed to judge how well the services that they provide meet the needs of the population as a whole. The different perspectives of hospital doctors and general practitioners are well illustrated by considering ophthalmology services. Bristol and Weston residents are served by an eye hospital with an international reputation. This hospital view of excellence has been well represented to health authorities through district and regional medical advisory mechanisms. Yet ophthalmology was perceived by general practitioners as one of the services most in need of improvement.

General practitioners' priorities for improving services differed from Bristol and Weston health authority's existing priorities and from those identified by the district's NHS trusts in their applications for self government. The health authority's priorities, reflecting national priorities, include all aspects of community care, but before our survey was undertaken the authority had no intention of reviewing its plans for ophthalmology or orthopaedic services except with respect to waiting times. Similarly, United Bristol Healthcare Trust identified neither ophthalmology nor orthopaedics as priorities in the short, medium, or long term. ${ }^{8}$ It is not yet clear how responsive providers will be to the views of service users.

Our survey does not identify which components of services identified as priorities for improvement can or should be changed. Further detailed information is being sought in a series of structured group discussions with selected general practitioners and in discussions with service providers.

\section{SURVEY'S ACHIEVEMENTS}

Closer links have been established between general practitioners and senior officers of the authority. We hope that these links will provide the basis for the development of population based assessments of the need for and outcomes of health care provision. Already, the survey has influenced the purchasing health authority to change its priorities to reflect more closely the priorities of general practitioners. This suggests that close links between general practitioners and purchasing health authorities may prove a more effective and efficient route for general practitioners to influence the provision of health care to their patients than fundholding.

The survey has also prompted the formation of a general practitioner and consultant liaison group, which aims at identifying ways that services might be improved. Although general practitioners and consultants practise with their patients' best interests at heart, their different practice settings give them different perceptions of patients' needs. There is a growing recognition that patients' needs are best met when those different perceptions of need are identified, shared, and valued.

We thank all general practitioners who completed questionnaires; Dr Tom Smythe and Dr Philip Carman for commenting on the draft questionnaire; and $\mathrm{Mr}$ Michael Shepherd, Mrs Angela Scanlon, and Mrs Angela Weaver for help with data processing and analysis.

1 Secretaries of State for Health, Wales, Northern Ireland, and Scotland. Working for patients: developing districts. London: HMSO, 1990.

2 Statistical Packages for the Social Sciences, SPSS PC + [computer program]. Chicago, Illinois: SPSS, 1988.

Cotus $1-2-3$ release $2 \cdot 2$ [computer program]. Cambridge, Massachusetts:
. Lotus, 1989 .

4 Morgan DR, Lamont TJ, Dawson JD, Booth C. Decontamination of instruments and control of cross infection in general practice. $B M \mathcal{F}$ 1990;300: 1379-80

5 Farmer A, Coulter A. Organization of care for diabetic patients in general practice: influence on hospital admissions. British fournal of General Practice 1990;40:56-8

6 Royal College of General Practitioners. Board of Censors, What sort of doctor? f R Coll Gen Pract 1981;31:698-702.

7 Maxwell RJ. Quality assessment in health. BMf 1984;288:1470-3.

8 United Bristol Healthcare Trust Project Team. Bristol Health Care Trust application for NHS trust status. Bristol: United Bristol Healthcare Trust,
1990 .

(Accepted 27 February 199l)
M. Georges Pilotelle has just issued in a handsome form a translation of Marat's tract, An Inquiry into the Nature, Cause, and Cure of a Singular Disease of the Eyes, hitherto unknown, and yet common, produced by the Use of certain Mercurial Preparations. London, 1776. The tracts issued by Marat during the time he was practising in London are excessively rare, so much so that their existence has been denied by some French writers on the Revolution. It is probably to put this denial out of court that $M$. Pilotelle has issued this reprint. Unfortunately, he has translated the tract into French instead of reprinting it in its original state. The reason he gives for not keeping to English is that "tout le monde n'est pas obligé de savoir cette langue." The translation has been made from the copy in the library of the Royal Medical and Chirurgical Society of London, which is the only one of which there is any public record. In 1775, Marat published an essay on Gleets, but of this no copy was known until quite lately, when Dr. J. F. Payne was fortunate enough to secure one in a volume of tracts purchased at auction. A reprint of these two tracts as Marat wrote them would make a volume of very curious interest. (British Medical fournal 1891;i:538) 